\title{
Important Addition to the McCord's Furniture Collection
}

\author{
by Conrad E. W. Graham \\ Curator of Decorative Arts, MoCord Museum of Canadian History
}

\author{
Art Cabinet \\ Ebonized wood, marquetry, tropical woods \\ Made by Herter Brothers, N.Y., about 1875 \\ Handpainted panel by Anna Eliza Hardy (1839-1934) \\ Gift of Mrs. Elizabeth Lewis \\ McCord Museum of Canadian History:M992.70.3.1-3
}

The McCord Museum as a museum of Canadian history is interested in furniture that was made or used in Canada and which reflects the evolving stylistic changes that have taken place over the centuries. The art cabinet was made in New York by the firm of Christian Herter (1840-1883), ${ }^{1}$ known as Herter Brothers which produced some of the finest furniture in the Aesthetic manner during the 1870s. The floral panel was painted by one of the most well-known floral artists in the United States, Anna Eliza Hardy (1839-1934). ${ }^{2}$ Anna Hardy living in Bangor, Maine painted with almost photographic precision and clarity, and her biographer in Leaflets of Artists ${ }^{3}$ described her work as "portraits of her friends"

The cabinet was purchased at the time of its construction by a Montrealer, Lieutenant-Colonel William Kennedy, and remained within the family until its recent donation to the museum. William Kennedy began his career as a cabinet-maker and eventually became an architect, who according to Lovell's Montreal Directory was responsible for the building of a number of houses on Dorchester Street. His early knowledge of wood may have been one of the reasons he acquired this piece. Cabinets of this quality were never mass-produced. It reflects the High Victorian taste for elaborate embellishments, and was originally intended to display decorative or sculptural objects. The cabinet compliments the museum's large collection of Victorian furniture from the 1840 s until the turn of the century.

\section{Notes}

1. Bulletin, Cleveland Museum of Art (Dec. 1982), 331.

2. Vatne, Diane and Kaiser Pauline. The Hardy Connection: Bangor Women Artists 1830-1900 (Bangor Historical Society, Bangor, Maine, 1992).

3. Mrs. A.L. Simpson, Leaflets of Artists (Bangor, Maine, 1893), 11. 
Notes and Comments

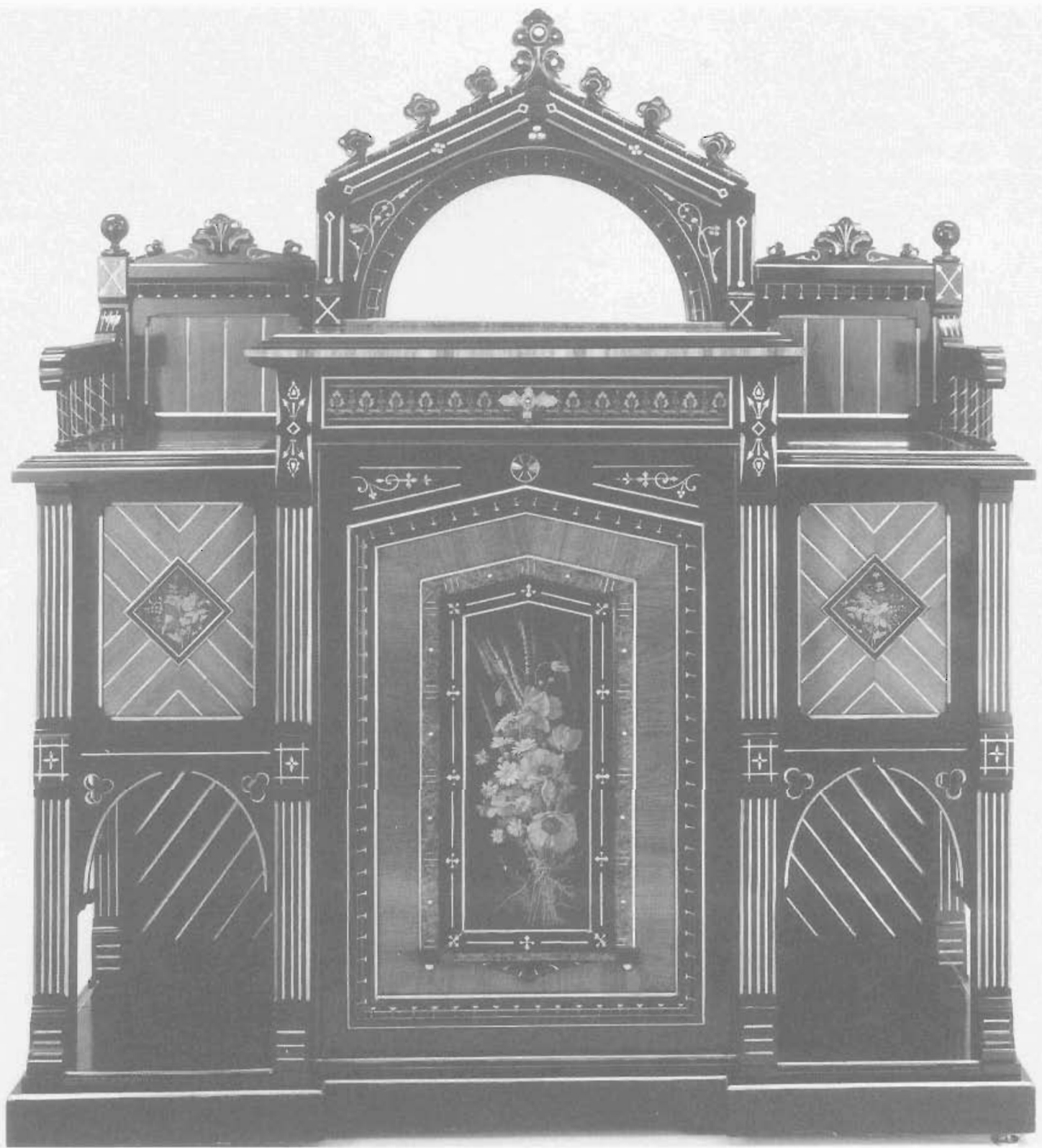

